\title{
Study on Individual Traffic Police On-Duty Behavior Analysis Method with Time Series Scheduling
}

\author{
Huai-jun Peng, ${ }^{1,2,3}$ Yong Qin,, ${ }^{1,2,3}$ Yan-fang Yang, \\ Zundong Zhang, ${ }^{4}$ and Abderrahim Chariete ${ }^{5}$ \\ ${ }^{1}$ State Key Laboratory of Rail Traffic Control and Safety, Beijing Jiaotong University, Beijing 100044, China \\ ${ }^{2}$ Beijing Research Center of Urban Traffic Information Sensing and Service Technologies, Beijing Jiaotong University, \\ Beijing 100044, China \\ ${ }^{3}$ School of Traffic and Transportation, Beijing Jiaotong University, Beijing 100044, China \\ ${ }^{4}$ Beijing Key Lab of Urban Intelligent Traffic Control Technology, North China University of Technology, Beijing 100041, China \\ ${ }^{5}$ OPERA Laboratory, University of Technology of Belfort-Montbéliard, 90000 Belfort, France
}

Correspondence should be addressed to Huai-jun Peng; hnphj@sina.com

Received 15 November 2014; Accepted 18 December 2014

Academic Editor: Chin-Chia Wu

Copyright (C) 2015 Huai-jun Peng et al. This is an open access article distributed under the Creative Commons Attribution License, which permits unrestricted use, distribution, and reproduction in any medium, provided the original work is properly cited.

In the traditional traffic police scheduling and dispatching, the applications of the position information are restricted. This paper presented a model of the traffic police on-duty behavior analysis based on time series, in order to improve the efficiency of traffic police scheduling and dispatching system. Firstly, it proposes the steps for the behavior analysis of individual traffic police onduty. Secondly, it elaborates division method of individual traffic police on-duty behavior from background element definition and semantic concept description. Thirdly the paper builds a model concerning individual traffic police on duty behavior by applying state automaton. Finally it describes the implementation methods of key technologies on individual traffic police on duty behavior.

\section{Introduction}

With the extensive application of wireless communication technology, GPS/BeiDou satellite positioning technology, and intelligent mobile terminals, location-based services (LBS) [1-3] had been rapidly developed and popularized. In the field of intelligent transportation, location-based service is the core technology of all kinds of intelligent transportation applications. Traffic information collection and services, traffic management and enforcement, vehicle security surveillance, vehicle navigation services, Internet of vehicles, and other types of application systems are based on LBS. In the aspects of traffic police duty management and dispatching, LBS are mainly used in dispatching and management $[4,5]$ of police cars and police officers; its application mode is the use of satellite positioning information of vehicular or handheld terminals to determine the location of police cars/police officers $[6,7]$, so that frontline commanders can monitor the state of the police by the location, track information of the traffic police, and dispatching of police resources by combining traffic conditions and information.

With the sustained rapid growth of city's economic construction and transportation, traffic management tasks are increasingly onerous. More and more police officers are deployed on roads to perform patrol duty tasks. How do we strengthen the management of road traffic police? How do we make full use of limited police resources? How do we complete traffic management works efficiently? The problems mentioned above are required to be solved for the government urgently. Taking Beijing as an example, by the end of 2012, on the one hand, citywide urban road mileage is up to more than 6200 kilometers, freeway is over 920 kilometers, the total mileage of highway is over 21,000 kilometers, and the total amount of vehicle ownership is 5.2 million. On the other hand, the average congestion time of weekday road network is nearly two hours, and the total number of on-duty traffic police officers on the road in citywide is just less than 5,000 people. Moreover, important 


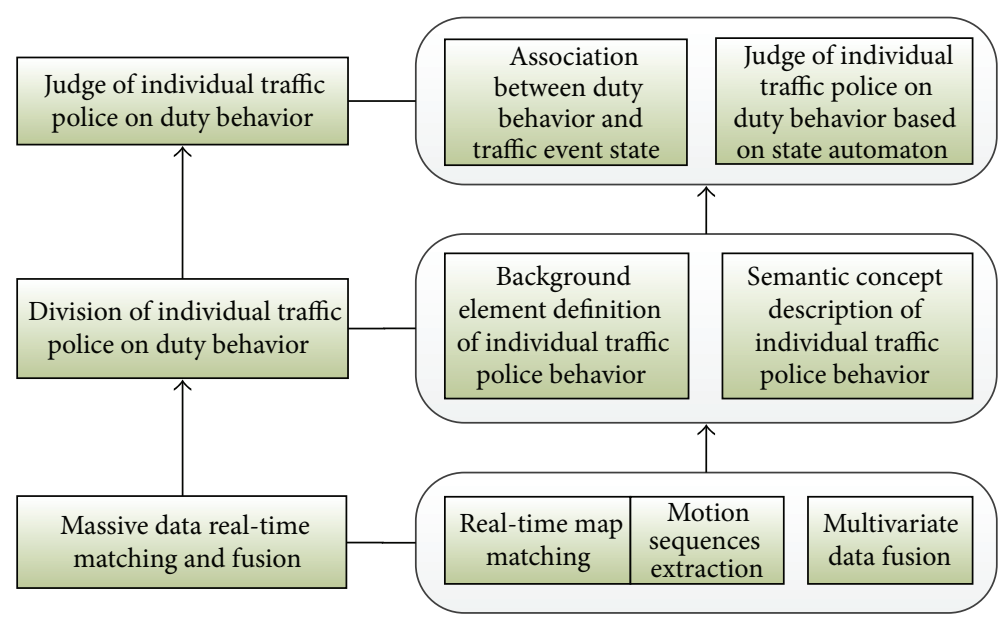

FIGURE 1: Steps for behavior analysis of individual traffic police on duty.

events such as weather disasters, key security task, also let the traffic command work in citywide become more and more onerous. In a word, police resources are too limited to meet the demand of traffic control.

Location-based services traffic police dispatching systems have been built in many cities. We can master the distribution of road police force and deploy police force in real time through the systems [8]. And it greatly improves the efficiency of the traffic command work. But without understanding the states of the traffic police on duty during dispatching police force based on the location information, the efficiency of the police resources deployment would be greatly reduced. In practice, the primary command staffs often communicate with the relevant police post firstly, and then the police post would send policeman to the corresponding place. These are too many intermediate steps that reduce the efficiency of the police dispatching.

In recent years, traffic behavior analysis methods are widely used in the study of pedestrians, drivers, and nonmotorized travelers and other types of traffic participants. A typical traffic behavior analysis research includes driving behavior analysis [9], transportation travel behavior analysis [10, 11], and pedestrian crossing traffic behavior analysis. However, researches for the traffic police on-duty behavior analysis are rare at home and abroad. This paper draws on domestic and foreign traffic behavior analysis research results, focuses on the study on behavior analysis method of individual traffic police on duty, and estimates the states of the traffic police on duty according to traffic police location information.

The paper is organized as follows. In Section 2, we proposed the main steps of individual traffic police on-duty behavior analysis method. In Section 3, we divided the behavior of individual police on duty by defining the background element and the semantic concept. In Section 4, we modeled individual traffic police on-duty behavior by applying state automaton. In Section 5, we described the implementation of key technologies of individual traffic police on-duty behavior analysis. We conclude the whole study in Section 6.

\section{The Steps of Individual Traffic Police On-Duty Behavior Analysis Method}

By using vehicular or handheld terminals and combining satellite positioning data with GIS systems, we can obtain location information of individual traffic police, which makes scheduling and management of police administration more flexible and changeable. If we can master the state of individual traffic police on duty, it will be able to further realize the scientific and efficient deployment of police. This paper presents an individual traffic police on-duty behavior analysis method based on time-series location information. The steps are as follows (see Figure 1).

(1) Real-Time Matching and Integration of Multiple Transport Resources and Massive Data That Oriented to Traffic Police On-Duty. By applying satellite positioning data and GIS systems real-time matching technology, we can obtain the spatial location of individual traffic police. Certain motion time series could be extracted after filtering trajectory data. By applying the traffic event information, traffic state information, and GIS system real-time matching technology, we can confirm the influence of traffic incidents and reflect location information of traffic incident to GIS map. By applying data fusion technology, we can realize the data fusion of satellite positioning, traffic events, and traffic states. It can lay foundation for the behavior analysis of the individual traffic police on duty.

(2) Division of Individual Traffic Police On-Duty Behavior. First of all, we define the background elements of individual traffic police on-duty behavior and give the corresponding mathematical descriptions from four aspects, including the on-duty area, traffic incident happening area, the traffic states, and the temporary leaving time of the police on duty. Secondly, more detailed introductions about semantic concepts of individual traffic police behaviors are given, such as onthe-job and off-the-job, which would be shown in Section 3. 
(3) Judge of Individual Traffic Police On-Duty Behavior. According to the relevant state between traffic police spatial location and each regional location in the GIS map, we study the correlation among the traffic incident states and model the individual traffic police on-duty behavior based on state automaton approach, in order to achieve the judge of individual traffic police on-duty behavior.

The core technology for division and judge of individual traffic police on-duty behavior is specifically addressed below.

\section{Division of Individual Traffic Police On-Duty Behavior}

3.1. Background Element Definition of Individual Traffic Police Behavior. To achieve semantic concept description of individual traffic police behavior, as first step we need to define the background element of individual traffic police behavior. Police officers' behaviors are susceptible to be influenced by factors that come from the Police Administration Department, by traffic incidents, such as the occurrence of a traffic accident and the change of traffic status. Firstly, it defines the duty area, traffic event happening area, and depicts the space location of police on duty; secondly, it defines the status of traffic incident and describes the factors of traffic police on duty; finally, it defines the police temporary away time and judges the undergo situation of police.

3.1.1. The Duty Area. Duty area refers to police management department prearranged area in advance for traffic police on duty. During working hours, traffic police officers are deployed in these areas.

We use $d_{i, l}^{R}$ to denote the distance between the traffic police $i$ and duty area $R$ and use $R_{i, l}$ to determine whether the traffic police $i$ are on duty in the area $l$ :

$$
R_{i, l}= \begin{cases}1, & d_{i, l}^{R} \leq d r_{i}, \\ 0, & d_{i, l}^{R}>d r_{i},\end{cases}
$$

where $R$ is the duty area, $i$ is the traffic police number, $l$ is onduty area number, and $d r_{i}$ is police positioning information drift. Among them, when $R_{i, l}=1$, traffic police $i$ are in the duty area $l$; when $R_{i, l}=0$, traffic police $i$ are out the duty area $l$.

Use $C_{i, l}^{R}(j)$ to judge whether the traffic police $i$ are approaching duty area $l$ at the time series $j$ :

$$
C_{i, l}^{R}(j)= \begin{cases}1, & d_{i, l}^{R}(j)-d_{i, l}^{R}(j-1)<0, \\ 0, & d_{i, l}^{R}(j)-d_{i, l}^{R}(j-1) \geq 0 .\end{cases}
$$

Among them, when $C_{i, l}^{R}(j)=1$, traffic police $i$ are approaching duty area $l$ at the time series $j$; when $C_{i, l}^{R}(j)=0$, traffic police $i$ are not approaching duty area $l$ at the time series $j$.

3.1.2. The Area Where Traffic Incidents Happen. The area where traffic incidents happen is divided into two kinds: one is accidents occurrence region, which mainly refers to the region traffic accidents scene belongs to; the other is the area where traffic state changes. The second kind area mainly refers to some special traffic state, such as traffic congestion.

Use $d_{i, m}^{S}$ to denote the distance between the traffic police $i$ and traffic incident area $S$, and use $S_{i, m}$ to judge whether the traffic police $i$ are in the traffic incident area $m$ :

$$
S_{i, m}= \begin{cases}1, & d_{i, m}^{R} \leq p_{i}, \\ 0, & d_{i, m}^{R}>p_{i},\end{cases}
$$

where $S$ is traffic incidents happening area, $m$ is traffic incident area number, and $p_{i}$ is traffic police positioning information drift. Among them, when $S_{i, m}=1$, traffic police $i$ are in the traffic incident area $m$; when $S_{i, m}=0$, traffic police $i$ are out the traffic incident area $m$.

Use $C_{i, m}^{S}(j)$ to judge whether the traffic police $i$ are approaching traffic incident area $m$ at the time series $j$ :

$$
C_{i, m}^{S}(j)= \begin{cases}1, & d_{i, m}^{S}(j)-d_{i, m}^{S}(j-1)<0, \\ 0, & d_{i, m}^{S}(j)-d_{i, m}^{S}(j-1) \geq 0 .\end{cases}
$$

Among them, when $C_{i, l}^{S}(j)=1$, traffic police $i$ are approaching traffic incident area $m$ at the time series $j$; when $C_{i, l}^{S}(j)=0$, traffic police $i$ are not approaching traffic incident area $m$ at the time series $j$.

3.1.3. Traffic Incident State. Based on the process of traffic incident, the traffic incident state is divided into three kinds of state, including "waiting to be processed," "under being processed," and "having been processed." In this paper, "waiting to be processed" state means traffic incident has occurred but police officers have not reached the traffic incident area; "under being processed" state means traffic incident has occurred and police officers have arrived at the traffic incident area; "having been processed" state refers to leaving the traffic incident area after police officers finish processing the traffic incident.

Use $P$ to denote traffic incident state, and when $P=1$, traffic incident occurs; when $P=0$, traffic incident does not occur. Traffic incident state is broken down into the following.

(1) Waiting State. When traffic incident occurs, that is, $P=1$, there are no traffic police in area $S$ and traffic police officers have been assigned to the scene.

Use $P_{1, m}$ to judge whether the traffic incident area $m$ where the traffic incident has occurred is in the waiting state to be processed:

$$
P_{1, m}= \begin{cases}1, & \sum_{i=1}^{n} S_{i, m}=0, P=1 \\ 0, & \sum_{i=1}^{n} S_{i, m} \neq 0, P=1 .\end{cases}
$$

Among them, when $P_{1, m}=1$, the traffic incident which happened in traffic incident area $m$ is in the waiting state; 
when $P_{1, m}=0$, the traffic incident in traffic incident area $m$ is not in the waiting state.

(2) Processing State. At the time traffic incident has occurred, that is, $P=1$, traffic police have arrived in area $S$ and are processing the traffic incident. Use $P_{2, m}$ to judge whether the traffic incident area $m$ is in processing state:

$$
P_{2, m}= \begin{cases}1, & \sum_{i=1}^{n} S_{i, m} \neq 0, \quad P=1, \\ 0, & \sum_{i=1}^{n} S_{i, m}=0, P=1 .\end{cases}
$$

Among them, when $P_{2, m}=1$, the traffic incident in traffic incident area $m$ is in processing state; when $P_{2, m}=0$, the traffic incident in traffic incident area $m$ is not in processing state.

(3) Processed State. After the police on duty have dealt with the traffic accident and sent a feedback to the police resources scheduling command system, the traffic incident area $m$ is in processed state. The formula is as follows:

$$
P_{3, m}= \begin{cases}1, & \text { finished handling traffic accidents, } \\ 0, & \text { not finished handling traffic accidents. }\end{cases}
$$

(4) Threshold Time for Temporary Off-the-Job. The definition of threshold time for temporary off-the-job $T$ aims to explain the threshold of the duration of traffic police temporary leaving time, during executing tasks in the duty area. Use $t$ to denote the time in which the traffic police have left the onduty area:

$$
T_{i}= \begin{cases}1, & t \leq T \\ 0, & t>T .\end{cases}
$$

When $T_{i}=1$, the duration of traffic police leaving time does not exceed the threshold $T$; otherwise, $T_{i}=0$.

\subsection{Semantic Concept Description of Individual Traffic Police} Behavior. By analyzing the behavior of traffic police during executing the task and police dispatching demands, the individual traffic police on-duty behavior could be classified into six kinds: on-the-job, temporary off-the-job, off-thejob, on the way to process traffic incidents, processing traffic incidents, and returning to post after dealing with traffic incidents. On the basis of the definition of individual traffic police behavior background element, semantic concepts of individual traffic police behavior are described in detail.

(1) State1: On-the-Job. On-the-job behavior is defined as, in the course of traffic police on duty, the behavior that has been in the duty area $R$. On-the-job behavior in police resources dispatching system is expressed as individual police's spatial position coordinate which is within the range of duty area $R$ in GIS map.

(2) State2: Temporary Off-the-Job. Temporary off-the-job behavior is defined as the behavior of duty personnel leaving the duty area, but leave time $t$ does not exceed threshold time for temporary off-the-job $T\left(T_{i}=1\right)$.

(3) State3: Off-the-Job. Off-the-job behavior is defined as the behavior of duty personnel leaving the duty area, and leave time $t$ exceeds the threshold time for temporary off-the-job $T\left(T_{i}=0\right)$.

(4) State4: On the Way to Process Traffic Incidents. Behavior of "on the way to process traffic incidents" is defined as traffic event state $P$ in traffic incidents happening area $S$ (number $m)$ is in the state of "waiting to be processed" $\left(P_{1, m}=\right.$ $1)$, and traffic police have received delegated tasks and are approaching traffic event area but have not arrived.

(5) State5: Processing Traffic Incidents. Processing traffic incidents behavior is defined as when traffic incident state is in an "under being processed" state $\left(P_{2, m}=1\right)$, and individual traffic police position is within traffic incidents happening area $S$.

(6) State6: Returning to Post after Processing Traffic Incidents. Behavior of returning to post after processing traffic incidents is defined as when the traffic incident state is in "having been processed" state $\left(P_{3, m}=1\right)$, and the trajectory of the traffic police is approaching duty area but has not reached the area.

\section{Judgment of Individual Police On-Duty Behavior}

4.1. Duty Behavior Associated with the State of the Traffic Incident. It is easy to see from elements definition of individual traffic police on-duty behavior that individual traffic police on-duty behavior is determined by satellite positioning location state of traffic police, as well as the state of the traffic incident. Therefore, the judgment of individual traffic police on-duty behavior is actually the judgments of the traffic accident state. Relationship between individual traffic police on-duty behavior and the state of the traffic incident is shown in Figure 2.

\subsection{Judgment of Individual Traffic Police On-Duty Behavior} Based on Finite State Automaton. The occurrence of traffic incident is an important influencing factor to the behavior of traffic police on duty. Because the occurrence of traffic incident can be described by discrete event dynamic systems, the finite state automata could be applied to model and analyze discrete event dynamic systems in general. In this paper, deterministic finite state automata principle is applied to judge the behavior of individual traffic police on duty. A deterministic finite state automaton $G$ is a quintuple:

$$
G=\left(Q, \Sigma, \delta, q_{0}, Q_{m}\right) .
$$

Among them $Q$ is the set of finite states, $\Sigma$ is the set of limited inputs, $\delta: Q \times \Sigma \rightarrow Q$ is state transition function, $q_{0} \in Q$ is the initial state, and $Q_{m} \subseteq Q$ is the set of termination states.

As for the judgment of individual traffic police on-duty behavior, $Q=$ (State1, State2, State3, State4, State5, State6), 


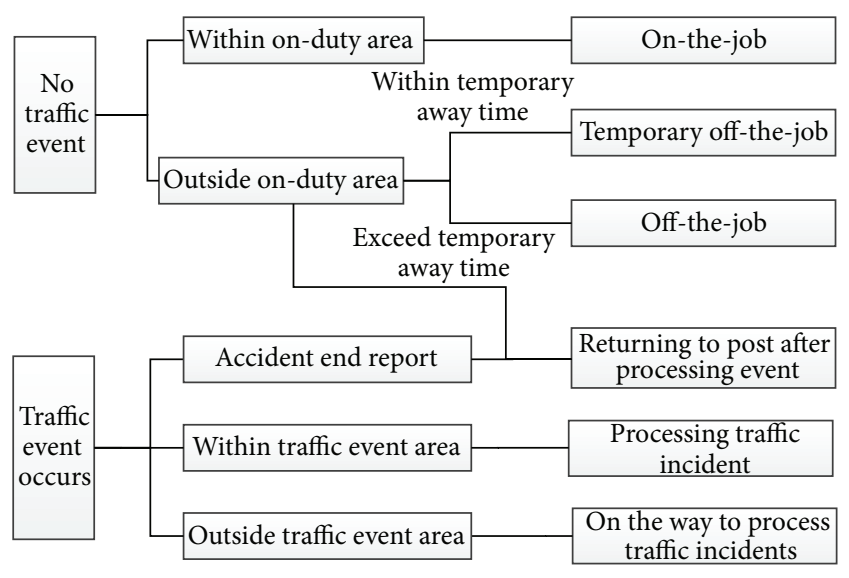

FIGURE 2: Illustration of partitioning logic for behavior analysis of individual traffic police on duty.

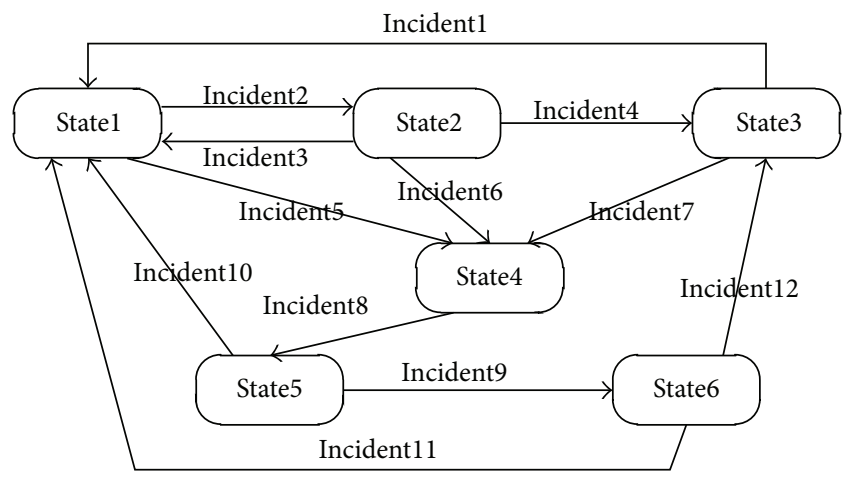

FIGURE 3: Illustration of behavior state transfer of individual traffic police on duty.

$\Sigma=\left(P, R, C^{R}, S, C^{S}, T\right), q_{0}=($ State 1$)$, and $Q_{m}=Q$. State transition of individual traffic police on-duty behavior is shown in Figure 3, and state transition function is shown in Table 1.

\section{Implementation of Key Technologies about Analysis of Individual Traffic Police On-Duty Behavior}

By applying individual traffic police on-duty behavior analysis method based on time-series location information and using ArcGIS and Oracle database programming, we achieve the division and judgment of individual traffic police on-duty behavior in the Beijing police resources scheduling command system. The implementation method is described in this section.

5.1. Implementation Method of Location State Judgment. The transfer conditions of judging individual traffic police onduty behavior are traffic police location state and traffic incident state. According to definitions of individual traffic police on-duty behavior, first of all, the distance between the location of the traffic police and the duty area (or traffic incident
TABLE 1: State transfer function.

\begin{tabular}{lll}
\hline $\begin{array}{l}\text { State } \\
\text { variables }\end{array}$ & Input & Output \\
\hline State3 & Incident 1: $P=0 \& R_{i, l}=1$ & State1 \\
State1 & Incident 2: $P=0 \& R_{i, l}=0 \& T_{i}=1$ & State2 \\
State2 & Incident 3: $P=0 \& R_{i, l}=1$ & State1 \\
State2 & Incident 4: $P=0 \& R_{i, l}=0 \& T_{i}=0$ & State3 \\
State1 & Incident 5: $P_{1, m}=1 \& S_{i, m}=0 \& C_{i, l}^{S}(j)=1$ & State4 \\
State2 & Incident 6: $P_{1, m}=1 \& S_{i, m}=0 \& C_{i, l}^{S}(j)=1$ & State4 \\
State3 & Incident 7: $P_{1, m}=1 \& S_{i, m}=0 \& C_{i, l}^{S}(j)=1$ & State4 \\
State4 & Incident 8: $P_{2, m}=1 \& S_{i, m}=1$ & State5 \\
State5 & Incident 9: $P_{3, m}=1 \& R_{i, l}=0 \& C_{i, l}^{R}(j)=1$ & State6 \\
State5 & Incident 10: $P_{3, m}=1 \& R_{i, l}=1$ & State1 \\
State6 & Incident 11: $R_{i, l}=1$ & State1 \\
State6 & Incident 12: $R_{i, l}=0 \& T_{i}=0$ & State3 \\
\hline
\end{tabular}

happening area) should be calculated. In GIS application, the distance should be calculated by the minimum distance from the point (i.e., the location of the traffic police) to the target plane (i.e., the duty area). We take the calculation of distance between traffic police $i$ and duty area $R$ as an example to show calculation steps.

(1) Determine whether spatial position coordinates $\left(X_{i}, Y_{i}\right)$ of traffic police $i$ are included in duty area $R$; if they are included in duty area, then $d_{i, l}^{R}=0$.

(2) Calculate the minimum distance $d_{i, l}^{e}$ from spatial position coordinates $\left(X_{i}, Y_{i}\right)$ of traffic police $i$ to each boundary in duty area $R$, wherein the minimum distance is $d_{i, l}^{R}$ and the formula is $d_{i, l}^{R}=\min \left(d_{i, l}^{e_{j}}, j=\right.$ $1,2,3, \ldots, n)$.

(3) Methods of seeking the minimum distance between point and boundary: firstly, draw a perpendicular line on the line segment through the given point and calculate the pedal coordinate. Secondly, determine whether the pedal is on the line segment, and if it is on the line segment then return to distance between the point and the pedal; if not, calculate the distance between this point and the endpoints of the line segments, separately. Finally, select the smaller one as the distance between the point and the plane.

ArcGIS provides ST_Distance function for the Oracle database SQL, and it can directly calculate the minimum distance from the point to the plane, so you can call directly when programming.

The judgment of traffic police location state needs to been implemented while receiving the traffic police positioning data. So the program is placed in the stored procedures of positioning database. The traffic police location $R_{i, l}$ and their duty area $C_{i, l}^{R}(j)$ are calculated every time the program is called. Moreover, traffic police location $S_{i, m}$ and the traffic incident area $C_{i, m}^{S}(j)$ are calculated too, when the traffic 


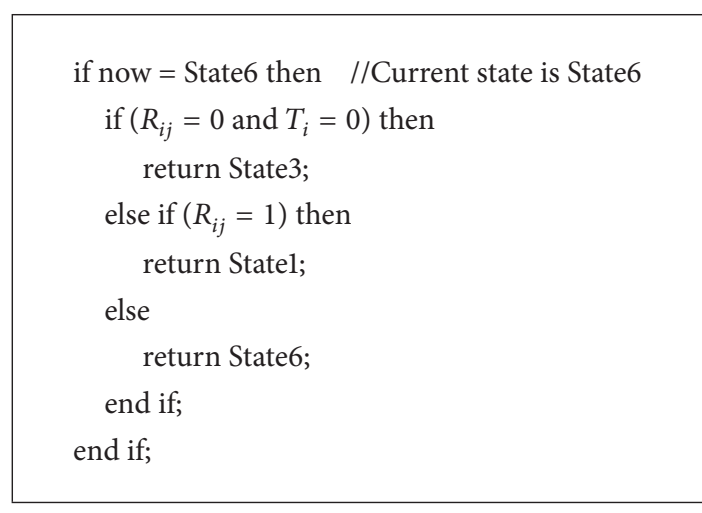

PSEUdocode 1

incident occurs and the traffic police are delegated to deal with the accident.

5.2. Implementation Method of State Transition Function. According to elements definition of individual traffic police on-duty behavior, each input element of the limited input set $\Sigma=\left(P, R, C^{R}, S, C^{S}, T\right)$ is ultimately determined by the traffic incident state and the traffic police location information. Therefore, when assessing traffic incident state and the traffic police location information data, it is needed to call state transition function to determine the state of individual traffic police on-duty behavior.

When the system is achieved, the state transition function is achieved by function of Oracle. The input variables are the current state and the value of each element in input set and the output variable is the transition state. The transition rule is realized according to state transition function condition. Partial pseudocode of the transition state is shown in Pseudocode 1.

\section{Conclusions}

As for the inadequate application of location information in traditional traffic police duty management and dispatching, this paper focuses on the actual needs of traffic police dispatching. A behavior analysis method of individual traffic police on duty based on time-series location information in the field of intelligent transportation is proposed, in order to solve the rationality and efficiency problems of deploying police force in dispatching. The method lays technical foundation for meticulous management of traffic police and dynamic scheduling.

This method takes traffic police location information, duty regional information, traffic incidents happening area, and traffic incidents state as input variables. The state judgment of individual traffic police on-duty behavior is achieved by modeling approach and applying GIS calculation methods. The existing technical conditions and data foundation are made full use of, which is conducive to system and project implementation.

Due to the judgment of location state relating to the GIS calculation method of minimum distance, its computa- tional complexity is relatively high, while the amount of traffic police location information data is large. In the implementation method, this paper presents the calculation of a designated traffic police duty area and delegated event, which would avoid large-scale cross-computing and greatly reduce the demand of computing resources. This method is also easier to implement in the system implementation engineering. In practical applications, it completes nearly a thousand of individual traffic police on-duty behavior analyses by using existing hardware and software resources in Beijing police resources dispatching system. Test results show that the proposed method is available.

\section{Conflict of Interests}

All the authors declare that there is no conflict of interests regarding the publication of this paper.

\section{Acknowledgments}

This paper is supported by the National Science \& Technology Pillar Program of China (no. 2014BAG01B02) and the Key Project of the Ministry of Public Security of China (no. 201302ZDYJ012).

\section{References}

[1] M. Mohr, C. Edwards, and B. McCarthy, "A study of LBS accuracy in the UK and a novel approach to inferring the positioning technology employed," Computer Communications, vol. 31, no. 6, pp. 1148-1159, 2008.

[2] B. Sadoun and O. Al-Bayari, "Location based services using geographical information systems," Computer Communications, vol. 30, no. 16, pp. 3154-3160, 2007.

[3] A. Marco, R. Casas, J. Falco, H. Gracia, J. I. Artigas, and A. Roy, "Location-based services for elderly and disabled people," Computer Communications, vol. 31, no. 6, pp. 1055-1066, 2008.

[4] Shenzhen Public Security Bureau Longgang Branch, "Police dispatch system: China," CN1609883 [P], April 2005.

[5] N. Zhao and Z. Li, "Optimize traffic police arrangement in easy congested area based on improved particle swarm optimization," Procedia-Social and Behavioral Sciences, vol. 138, pp. 408-417, 2014.

[6] G. Chen, "The research and realization on police vehicles direction dispatching system based on the 3G technologies," Information Technology \& Informatization, no. 1, pp. 30-32, 2009 (Chinese).

[7] Y.-k. Zhong, Z.-d. Yu, L.-p. He et al., "Application of GIS-T in Guangzhou intelligent traffic management and command," Guangdong Gongan Keji, vol. 18, no. 1, pp. 39-44, 2010 (Chinese).

[8] J.-C. Feng, Y.-L. Shi, and J.-F. Song, "Design and realization of police wagon real-time inspection system based on GPS and GIS," Modern Electronics Technique, vol. 28, no. 18, pp. 21-22, 25, 2005 (Chinese).

[9] Shouke Software, "Tetra mobile phone with GIS and PDA functions and its implementation: China," CN1968468 [P], May 2007. 
[10] M. Basset, C. Cudel, V. Georges, S. Mouhoub, and J. Baujon, "Automatic region of interest tracking for visual characterization of the driver's behaviour," in Proceedings of the IEEE Intelligent Vehicles Symposium, pp. 335-338, IEEE, June 2004.

[11] R. Ahas, A. Aasa, S. Silm, and M. Tiru, "Daily rhythms of suburban commuters' movements in the Tallinn metropolitan area: case study with mobile positioning data," Transportation Research Part C: Emerging Technologies, vol. 18, no. 1, pp. 45-54, 2010. 


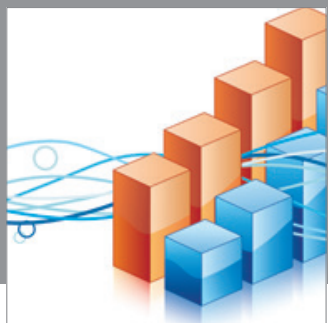

Advances in

Operations Research

mansans

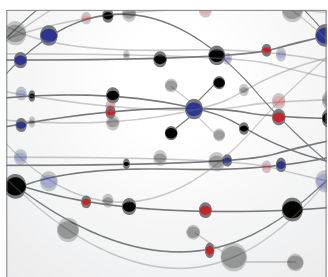

The Scientific World Journal
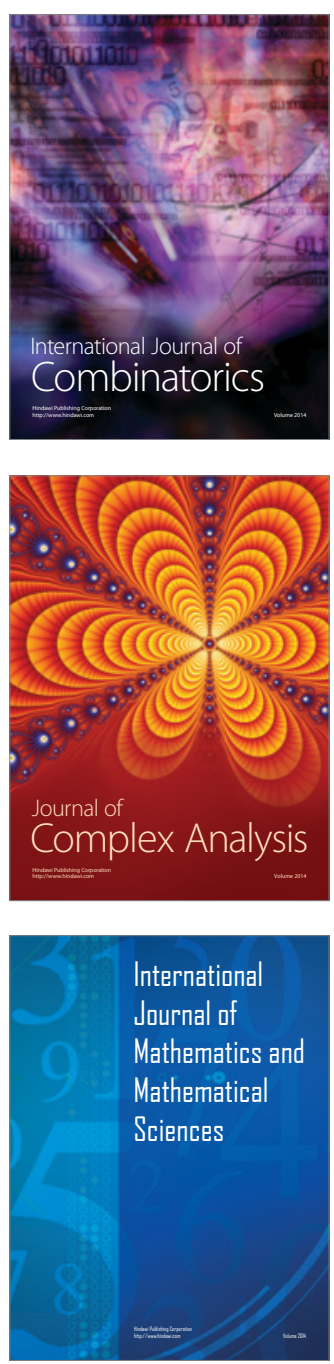
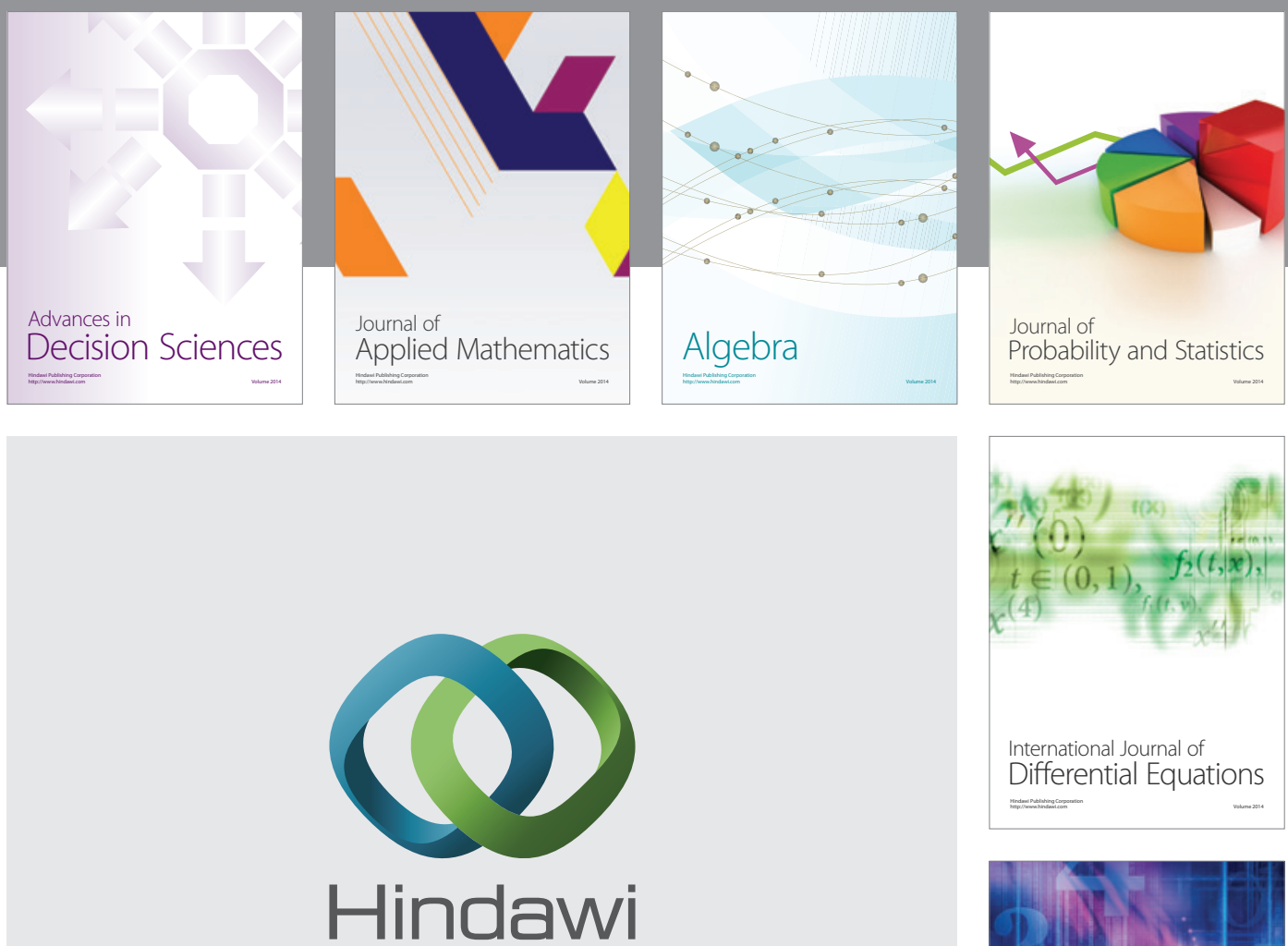

Submit your manuscripts at http://www.hindawi.com
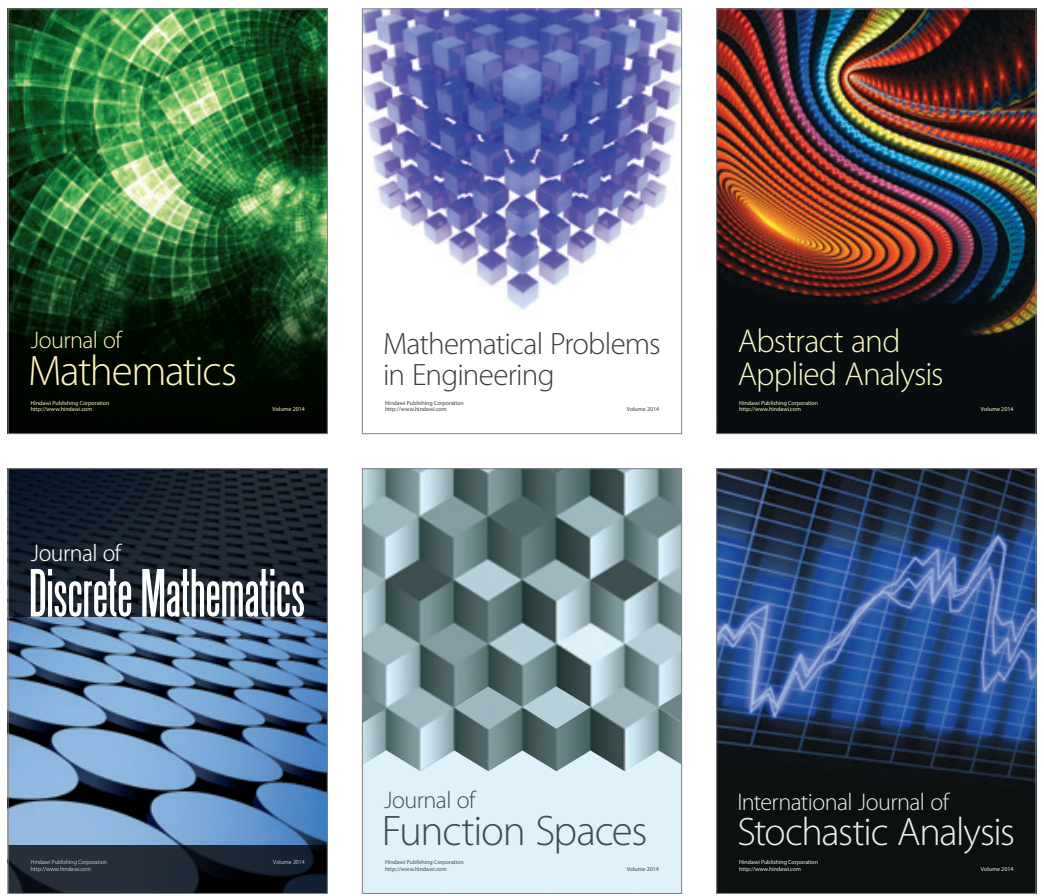

Journal of

Function Spaces

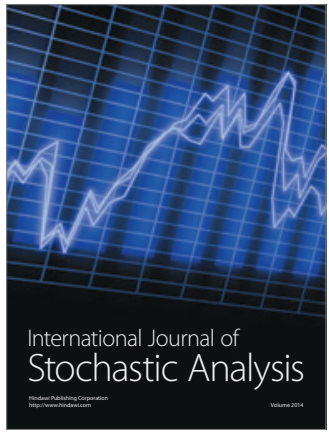

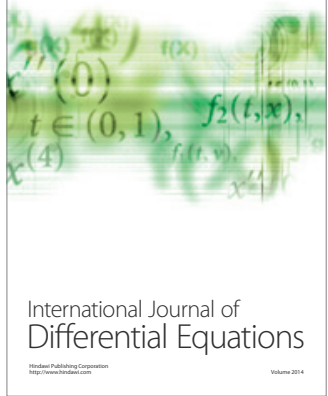
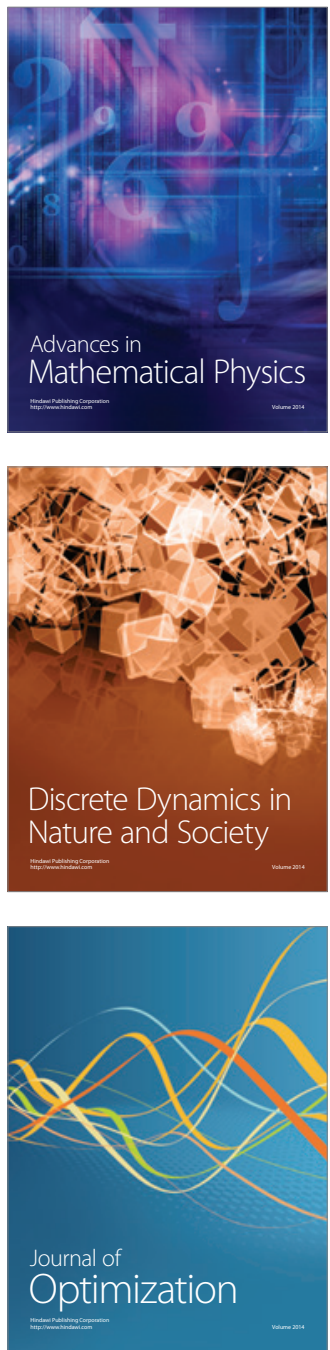